\title{
In memoriam: Yasuharu Nimura MD, PhD, 1923-2015
}

\author{
Kunio Miyatake ${ }^{1}$
}

Published online: 16 November 2015

(C) Japanese Society of Echocardiography 2015

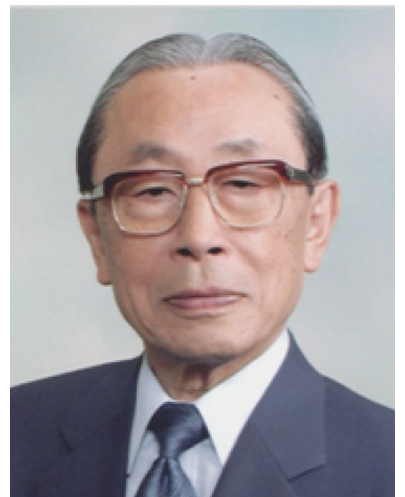

On March 23, 2015, Dr. Yasuharu Nimura, MD, PhD, who was an honorary member of the Japanese Society of Echocardiography and a developer of ultrasonic Doppler cardiography, passed away at the age of 91 years. We heard, with deep regret and a sense of loss, of the passing of Dr. Nimura, who devoted himself exclusively to studies in the field of medical ultrasonics.

Dr. Nimura was born in Osaka, Japan in 1923. After graduation from the Division of Physics, School of Science, Kyoto University, in 1945, he entered Osaka University School of Medicine and graduated from it in 1951. Thereafter, he belonged to the First Department of Medicine, Osaka University School of Medicine (First Department of Medicine led by Professor Yoshida), and studied vectorcardiograms at the heart laboratory.

Kunio Miyatake

kmiyatak@ommc-hp.jp

1 National Hospital Organization, Osaka-Minami Medical Center, Osaka, Japan
In 1972, he was promoted to associate professor and took leadership of research and clinical treatment.

In 1977, the National Cardiovascular Center was established and he became vice director of the Research Institute, the National Cardiovascular Center.

In 1981, he was promoted to director of the Research Institute.

In 1989, he reached official retirement age and retired from his position. He was then appointed as an honorary director of the Research Institute, the National Cardiovascular Center.

In 1955, Dr. Nimura read a newspaper article about the study of the ultrasonic Doppler technique that Associate Professor Shigeo Satomura, the Institute of Scientific and Industrial Research, Osaka University, had developed to measure vibrations of a board. Dr. Nimura visited Associate Professor Satomura to discuss the possibility of medical application of this technique. Both of them intended to promote medical application of the ultrasonic Doppler technique and agreed to launch a joint research project. This was an interdisciplinary joint research project for medical application of the ultrasonic Doppler technique promoted by Associate Professor Satomura, who was in charge of development of devices, and Dr. Nimura, who was in charge of exploration of medical significance. Subsequently, the two researchers started the first-ever medical application project of the ultrasonic Doppler method. For the first 6 months, Dr. Nimura placed the probe from the chest wall to the heart, but the sounds detected were only noise and no special meaning could be obtained. In the face of hardship, they came very close to giving up the project. However, they adjusted various conditions and finally detected high-frequency weak 
signals in a cyclic fashion. Dr. Nimura, an expert in the field of physics, examined the weak signals and assumed that the reflector might be a quickly moving heart valve. He compared his findings with ECGs and phonocardiograms and finally found that the signals were Doppler signals emitted at the time of opening and closing of the heart valve (Fig. 1). In the spring of 1956 , at a scientific conference of the Japanese Circulation Society, Dr. Nimura gave a presentation titled "Study on cardiac function test using ultrasonic doppler method". Afterward, Dr. Nimura conducted experiments on dogs to demonstrate the significance of these Doppler signals and relate the signals to heart valve movement. He carried out many studies and concluded that the signals detected were Doppler signals emitted at the time of opening and closing of the heart valve. This phenomenon was demonstrated by the subsequent simultaneous recording of M-mode echocardiogram and ultrasonic Doppler cardiogram. Thus, Dr. Nimura's presentation at the scientific conference in 1956 was the world's first report on "application of the ultrasonic Doppler method to cardiac examination".

After his development of ultrasonic Doppler cardiography, Dr. Nimura continued to promote the research project for clinical application of the technique. He had to make special efforts to promote the clinical application research, which made little progress because of insufficient development of peripheral technology. During this difficult period of the predawn of the ultrasonic Doppler technique,
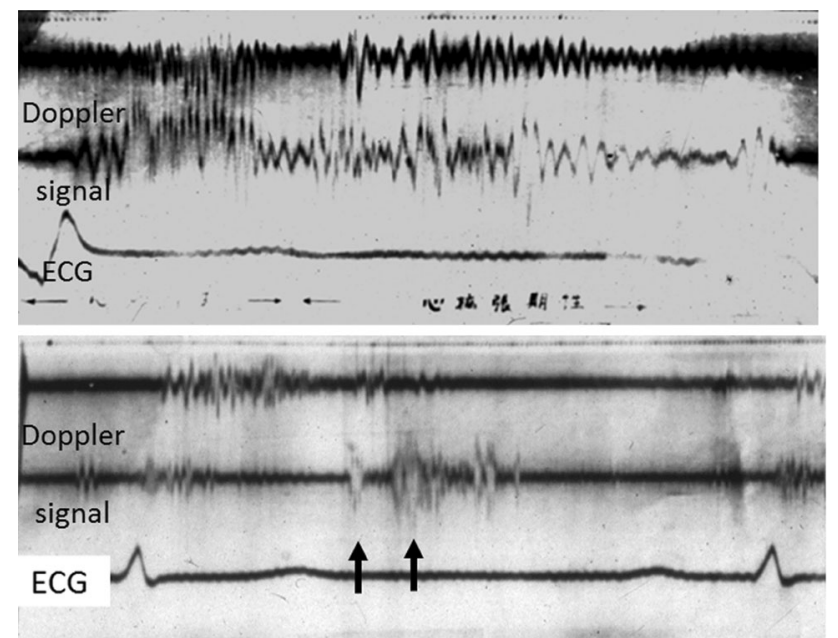

Fig. 1 Dr. Nimura recorded the typical rough signal, using the first Doppler apparatus in 1955 (upper panel). First applications of Doppler ultrasound to the heart. Thereafter, high frequency ingredients were taken out using a high pass filter and amplifying the heart Doppler signals (lower panel). It was the birth of the Doppler technique with the report of Drs. Nimura and Satomura on the examination of the heart with the ultrasonic Doppler method in Osaka, Japan. Thus, the Japanese researchers, particularly Dr. Nimura, were true pioneers of ultrasonic Doppler cardiography he created a path to the future with a strong belief and developed a technology to combine echocardiography and ultrasonic Doppler cardiography. In this manner, Dr. Nimura succeeded in the clinical application of ultrasonic Doppler cardiography to cardiac examination. Dr. Nimura developed ultrasonic Doppler cardiography in collaboration with Associate Professor Satomura. However, the first paper in English was published under the name of Associate Professor Satomura alone. Therefore, outside of Japan, Dr. Nimura has not been known as a researcher who developed this technique in collaboration with Associate Professor Satomura. Dr. Nimura placed a probe over the chest wall, recorded the cardiac movement, conducted various examinations, and finally concluded the signals reflected movement of the heart valve. Dr. Nimura felt regret that overseas researchers did not know that the ultrasonic Doppler technique was developed by two Japanese researchers, Dr. Nimura and Associate Professor Satomura.

Around 1967, under the order of Professor Yoshida, his supervisor, Dr. Nimura engaged in preparation for establishment of the National Cardiovascular Center and prepared a basic plan. In 1977, he was appointed to a new position at the National Cardiovascular Center. Afterward, he promoted various scientific projects of clinical ultrasonography and clinical research, and published many papers internationally.

Dr. Nimura accomplished many achievements and completed his work as a world leader of ultrasonography. He made efforts to widely diffuse ultrasonography as a routine diagnostic technique. He served as president of the International Cardiac Doppler Society, and held a global scientific meeting in Kyoto in 1986 (Fig. 2). For his significant contribution to the development of ultrasonic Doppler cardiography and clinical application of the

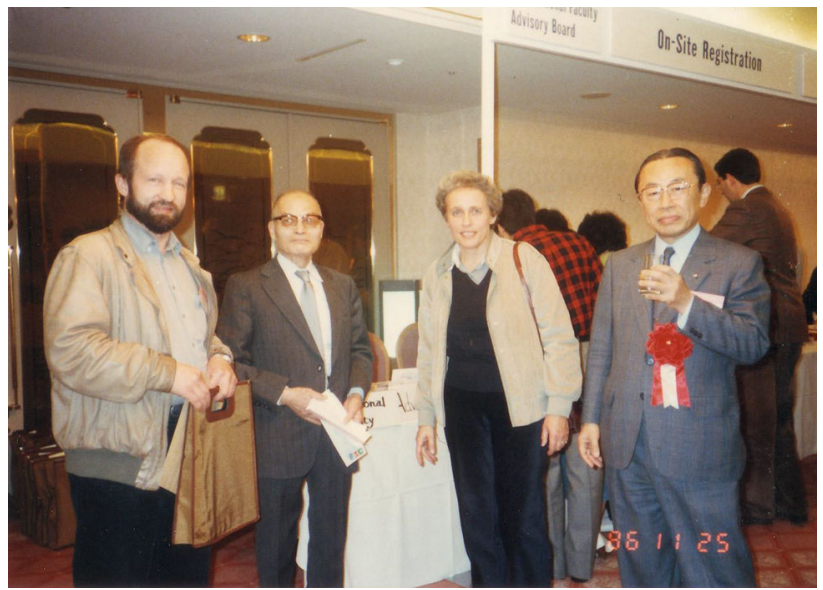

Fig. 2 Dr. Nimura, the president of International Doppler Society Meeting held in Kyoto, 1986 
ultrasonic diagnostic technique, Dr. Nimura received the award of the Director-General of the Science and Technology Agency, the Medal with Purple Ribbon (Shijuhosho), and the Order of the Rising Sun, Gold Rays with Neck Ribbon (Kyokujitsuchujusho). Moreover, he received the Honor Award and the Special Award from the society.

The Japanese Society of Echocardiography highly appreciates Dr. Nimura's achievements, including development of ultrasonic Doppler cardiography as the platform technique of the society, its clinical application, and establishment of the technique as a routine examination method. In honor of Dr. Nimura, the society organizes the 'Nimura Lecture' in its scientific conference.

We have fond memories of Dr. Nimura. He took a very rigorous approach toward scientific research and gave us strict advice before giving presentations at the meetings. The memory of the late Dr. Nimura is still cherished in our hearts. We have much respect for his attitude as a dedicated academic researcher and appreciate his high virtue and excellent achievements. We express profound thanks to Dr. Nimura and bless his memory. 